\title{
ANALISIS EFISIENSI SUMBER DAYA DAN PRODUKSI BERSIH DI DESA WISATA PULESARI, SLEMAN, YOGYAKARTA
}

\author{
Muhammad Dzulkifli \\ Politeknik Negeri Jember \\ dzulkifli@polije.ac.id \\ Jussac Maulana Masjhoer \\ Sekolah Tinggi Pariwisata Ambarrukmo \\ jussacmaulana@stipram.ac.id
}

\begin{abstract}
This study aims to describe the results of the Resource Efficiency and Cleaner Production (RECP) analysis based on the RECP assessment indicators from UNIDO and to give RECP recommendations based on the result of the assessment. The analysis shows that in the management of Desa Wisata Pulesari (Dewi Pule), there are three main activities that uses many resources, namely homestay, Dasa Wisma kitchen and Pendopo. The result says, inefficiencies of energy were found in kitchens and homestays. The use of energy in homestays can be saved by replacing ordinary lamps with LED lights. Efficiency in the kitchen can be done by using magnets on the gas hose and using a healthy energy efficient stove (TSHE) stove. From the results of these recommendations, Dewi Pule has the potential to reduce carbon by $65,279.9$ CO2eq kg / year and in terms of economy Dewi Pule has the potential to save a total of IDR 33,412,106 / year. The assessment and application of RECP in a tourism village requires adjustments to the indicators. This is because the character of the resources and energy use in tourism villages is very different from the industries that have implemented the RECP method from UNIDO.
\end{abstract}

Keywords: Efisiensi Sumberdaya, Produksi Bersih, Desa Wisata, Pulesari

\section{Pendahuluan}

Pariwisata berbasis masyarakat (CBT) adalah salah satu bentuk usaha pariwisata yang lekat dengan masyarakat, memberdayakan masyarakat lokal, mengelola pertumbuhan pariwisata dan mencapai kesejahteraan mereka, pariwisata berbasis komunitas termasuk dalam kerangka pembangunan yang berkelanjutan secara ekonomi, sosial dan lingkungan (Krisnani \& Darwis, 2010; Caribbean Tourism 
Organization, 2003; Sustainable Tourism Cooperative Research Centre, 2010). Pariwisata berbasis masyarakat mendukung konsep pariwisata berkelanjutan yang memperhatikan pertumbuhan ekonomi lokal, konservasi dan apresiasi terhadap kearifan lokal (Syafi \& Suwandono, 2015; Zakaria \& Suprihardjo, 2014). Di Indonesia, jenis pariwisata berbasis masyarakat direpresentasikan dengan desa wisata, kampung wisata dan atau wisata pedesaan. Pada tahun 2012, Kementerian Pariwisata menargetkan 960 desa wisata di Indonesia (Kemenparekraf, 2012) dengan homestay dan produk budayanya. Kemudian, pada tahun 2017 lalu Kementerian Pariwisata menargetkan kembali sebanyak 20.000 homestay di desa wisata (Astuti, 2017).

Desa wisata merupakan rural tourism atau wisata pedesaan. Beberapa menggunakan istilah ekowisata sebagai konsep, namun intinya adalah memanfaatkan potensi alam, budaya dan buatan, pelibatan masyarakat lokal dalam segala proses kepariwisataan mulai dari perencanaan, pembuat keputusan, pengelolaan dan pengembangan serta pembagian hasil. Desa wisata mendukung prinsip-prinsip pariwisata berkelanjutan dan dinilai sebagai pariwisata inti rakyat dengan konsep lokalitas, gotong royong, musyawarah dan adil (Dewi, Fandeli, \& Baiquni, 2013; Priasukmana \& Mulyadin, 2001 ; Damanik, 2013).

Desa Wisata Pulesari (Dewi Pule) merupakan salah satu desa wisata berstatus mandiri yang telah ditetapkan oleh Dinas Pariwisata Kabupaten Sleman. Kriteria ini diberikan melihat dari pengelolaan Dewi Pule yang telah memiliki pendapatan sebesar 4.5 milyar di tahun 2018 dengan kunjungan wisatawan mencapai diatas 50.000 orang sejak tahun 2015. Selain itu, Dewi Pule melibatkan sebanyak 80\% dari total warganya dalam kegiatan kepariwisataan baik langsung maupun tidak langsung. 
Tabel 1. Jumlah Kunjungan dan Pendapatan Desa Wisata Pulesari

\begin{tabular}{|c|c|c|c|}
\hline \multirow[t]{2}{*}{ Tahun } & \multicolumn{2}{|c|}{ Jumlah Kunjungan } & \multirow{2}{*}{$\begin{array}{l}\text { Jumlah Pendapatan } \\
\text { (Rp) }\end{array}$} \\
\hline & Wisman & Wisnus & \\
\hline 2013 & 0 & 6.035 & - \\
\hline 2014 & 14 & 32.178 & - \\
\hline 2015 & 28 & 50.271 & 1.448 .500 .000 \\
\hline 2016 & 32 & 52.947 & 2.159.286.000 \\
\hline 2017 & 47 & 63.927 & 3.284.583.000 \\
\hline 2018 & 185 & 72.738 & 4.507 .846 .000 \\
\hline
\end{tabular}

Sumber: Manajemen Dewi Pule, 2019

Produktifitas pariwisata yang terus meningkat di Dewi Pule tentunya tidak lepas dari konsumsi sumberdaya alam dan energi. Wisatawan yang datang menggunakan akan energi yang lebih banyak seperti pengisian daya untuk handphone, kamera, laptop, dan sebagainya. Pemakaian air dan bahan baku makanan pun meningkat menyesuaikan kebutuhan konsumsi wisatawan. Hal ini menggambarkan bagaimana sebuah aktifitas kepariwisataan pada akhirnya menghasilkan limbah baik cair, padat dan gas karbon di sebuah desa wisata (Ahmad, Draz, Su, Ozturk, \& Rauf, 2018; Sunlu, 2003).

Program Effisiensi Sumberdaya dan Produksi Bersih (ESPB) merupakan sebuah alat dari United Nations Industrial Development Organization (UNIDO) yang digunakan untuk menilai penggunaan energi, sumberdaya dan produksi bersih. Program ini bertujuan untuk mengharapkan/menghendaki adanya perubahan sikap dan cara berfikir, sistem pengelolaan lingkungan yang bertanggung jawab dan mengevaluasi pilihan-pilihan teknologi yang digunakan. ESPB juga bertujuan 
mengurangi limbah dan emisi, dengan penggunaan bahan dan energi yang lebih efisien, melalui modifikasi dalam proses produksi, bahan, teknis pelaksanaan, produk dan jasa (Berkel, 2014; Hens et al., 2018; UNIDO \& UNEP, 2015). Sebelumnya, program ESPB lebih banyak diterapkan dan lebih cocok pada lingkup industri dengan skala besar, namun sebenarnya juga dapat diterapkan pada industri kecil dan menengah. Beberapa studi mengenai ESPB telah dilakukan di berbagai usaha kecil dan menengah (lihat Agyeiwaah, 2019; Berkel, 2014).

Pada dasarnya pengelolaan desa wisata adalah siklus hidup masyarakat di desa dengan segala aktifitas kesehariannya. Sehingga ESPB dapat merujuk pada penilaian ESPB di tingkat rumah tangga. Perbedaan yang menarik adalah aktifitas keseharian di desa akan meningkat seiring jumlah wisatawan yang berkunjung dan menggunakan sumberdaya dan energi dalam memenuhi kebutuhannya. Oleh karena itu, penelitian ini berusaha untuk menggambarkan penilaian ESPB yang diterapkan sekaligus memberikan rekomendasi mengenai efisiensi sumberdaya, energi dan produksi bersih pada desa wisata.

\section{Metodelogi}

Metode penilaian ESPB menggunakan pendekatan yang dimulai dengan mengidentifikasi, kemudian mengevaluasi lalu memberikan rekomendasi, kemudian menerapkan dan membuatnya menjadi program yang berkelanjutan. Penilaian membutuhkan siklus dan perbaikan yang terus menerus. Penilaian ESPB memerlukan data dasar yang terdiri dari penggunaan sumber daya dan energi, limbah dan polusi yang ditimbulkan dari penggunaan energi dan sumberdaya, hunian kamar, dan jumlah tamu. Data-data diperoleh dari catatan pengelola desa wisata dan catatan rumah tangga (pembelian dan pembayaran tagihan, meteran listrik, dll.) observasi dan wawancara.

Metode ESPB menggunakan tiga tahap proses penilaian (assessment), diantaranya yaitu: 
Memulai; membuat komitmen dan memastikan keterlibatan manajemen serta staf, mendokumentasikan kinerja data awal serta biaya yang dikeluarkan dengan menggunakan indikator ESPB. Tugas utama dalam fase ini adalah melibatkan manajemen dan staf dan menilai kinerja serta biaya beban dasar.

Menilai Proses Pengoperasian dan Prakteknya di lapangan; dilakukan untuk memetakan, meninjau dan, jika memungkinkan mengidentifikasi tolok ukur kinerja operasional serta memilih bidang dan tindakan prioritas untuk penerapan ESPB. Tugas utama dalam fase ini adalah memetakan aktivitas dan alur proses, memeriksa cara kerja operasional, praktik dan tolok ukur kinerja, serta penetapan prioritas dan tindakan.

Mengembangkan Solusi; ditujukan untuk menyusun daftar ESPB yang layak, memberikan solusi untuk tiap bidang prioritas ESPB yang ditetapkan, penyesuaian opsi-opsi ESPB dan penilaian terhadap teknis pelaksanaan, lingkungan dan kelayakan ekonomi. Tugas utama fase ini adalah pengembangan opsi ESPB dan evaluasi kelayakan.

\section{Hasil dan Pembahasan}

\section{Hasil}

\section{Situasi Awal}

Desa Wisata Pulesari terletak di ujung utara Yogyakarta. Merupakan daerah pertanian dengan dua puluh enam mata air yang mengalir dari dua aliran sungai yang mengapit kampung ini yaitu sungai Bedog Barat sungai Bedog Timur. Sungai digunakan sebagai sumber air untuk mencuci dan mandi para penduduk. Untuk keperluan minum, kebanyakan warga menggunakan air dari sumur dengan kedalaman sekitar 10 meter hingga 15 meter. Dewi Pule terletak di lereng Merapi, berjarak $\pm 12 \mathrm{~km}$ dari puncak Gunung Merapi dengan ketinggian sekitar 600-700 mdpl. Sebagian besar warganya adalah petani salak dan peternak ikan air tawar. 
Desa wisata Pulesari menawarkan atraksi budaya dan alam seperti tarian tradisional, jelajah sungai, live in (tinggal di rumah warga dan mengikuti aktifitas masyarakat lokal), outbound, fun games dan kuliner lokal. Berdasarkan data manajemen Dewi Pule pada tahun 2018, terdapat 57 homestay dengan 150 kamar, 6 dapur kelompok, 2 Pendopo umum, dan 6 toilet umum. Tidak semua wisatawan menginap di Pulesari, sebagian tamu hanya bermain outbound dan makan siang. Tabel di bawah ini menunjukkan produktivitas Dewi Pule dalam penggunaan sumber daya dan menghasilkan limbah pada tahun 2015:

Tabel 2. Input Sumberdaya dan Limbah Tahun 2015

\begin{tabular}{|c|c|c|c|}
\hline \multicolumn{2}{|l|}{ Input Sumberdaya } & \multicolumn{2}{|l|}{ Limbah dan Emisi } \\
\hline $\begin{array}{l}\text { Total penggunaan } \\
\text { material }\end{array}$ & $52849 \mathrm{~kg} /$ tahun & Total limbah & 2,6 ton/tahun \\
\hline $\begin{array}{l}\text { Total penggunaan } \\
\text { energy }\end{array}$ & $\begin{array}{l}\text { 569596,15 } \\
\text { kWh/tahun }\end{array}$ & Total emisi & $\begin{array}{l}400299 \quad \mathrm{kgCO} 2- \\
\text { eq/tahun }\end{array}$ \\
\hline $\begin{array}{l}\text { Total penggunaan } \\
\text { air }\end{array}$ & $4846,3 \mathrm{~m} 3 /$ tahun & $\begin{array}{l}\text { Total limbah } \\
\text { cair }\end{array}$ & 2907,7 m3/tahun \\
\hline
\end{tabular}

\section{Pemetaan Aktifitas dan Alur}

Untuk mengetahui permasalahan dan memberikan solusi dalam penerapan ESPB dimulai dengan inventarisasi kegiatan utama dan pemetaan aliran material, air dan energi. Bagian ini memberikan gambaran lengkap kegiatan kepariwisataan di desa wisata Pulesari yang memiliki pengaruh pada penggunaan sumber daya dan penghasil limbahnya. Peta aktivitas dan alur aktivitas utama ditampilkan pada gambar di bawah ini: 


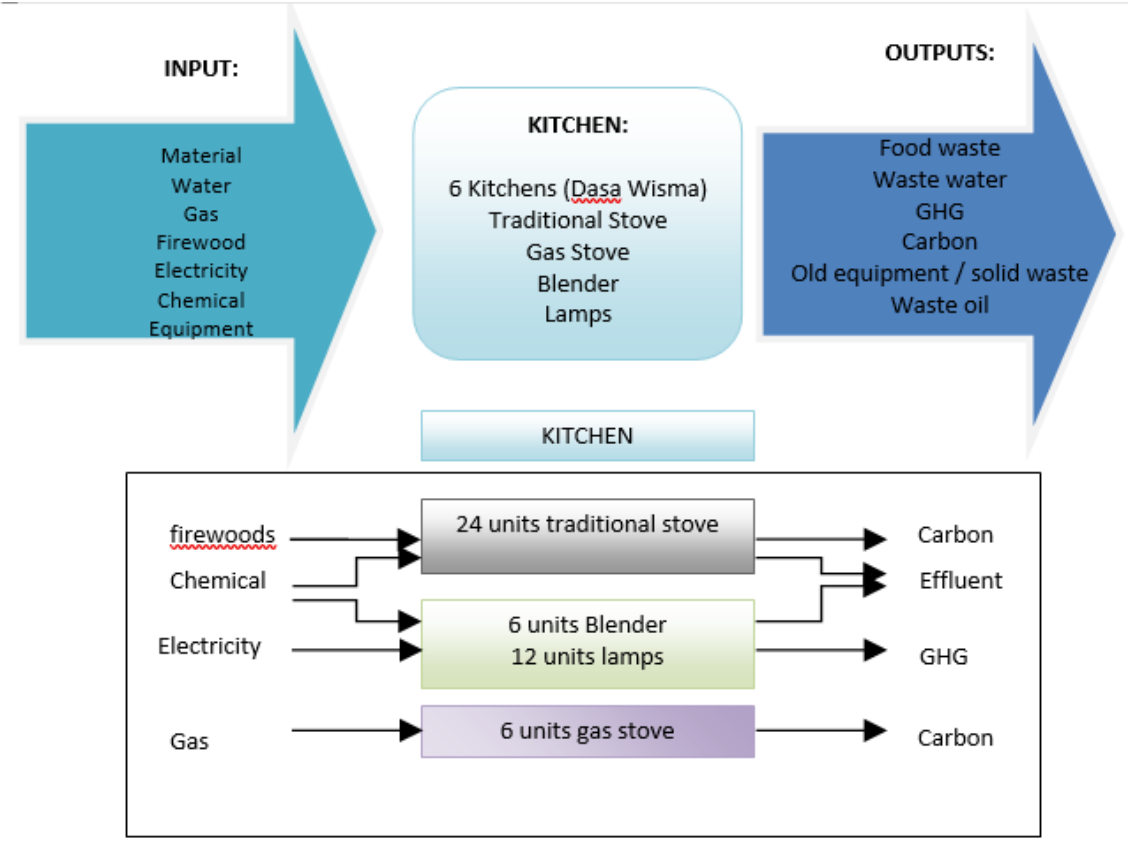

Gambar 1. Alur sumberdaya dan energi di dapur
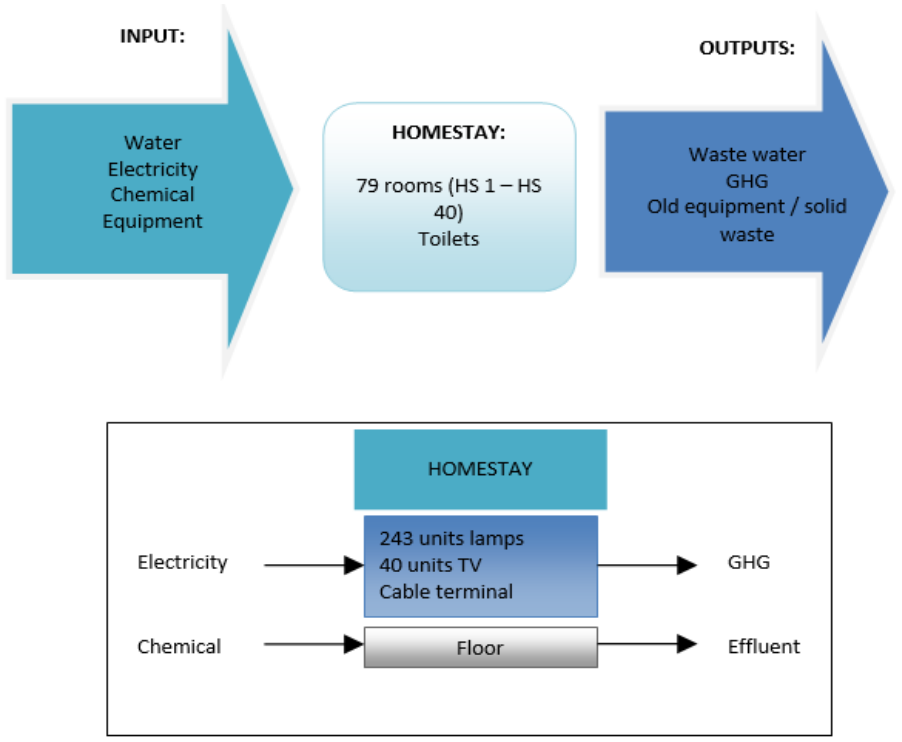

Gambar 2. Alur sumberdaya dan energi di Homestay 


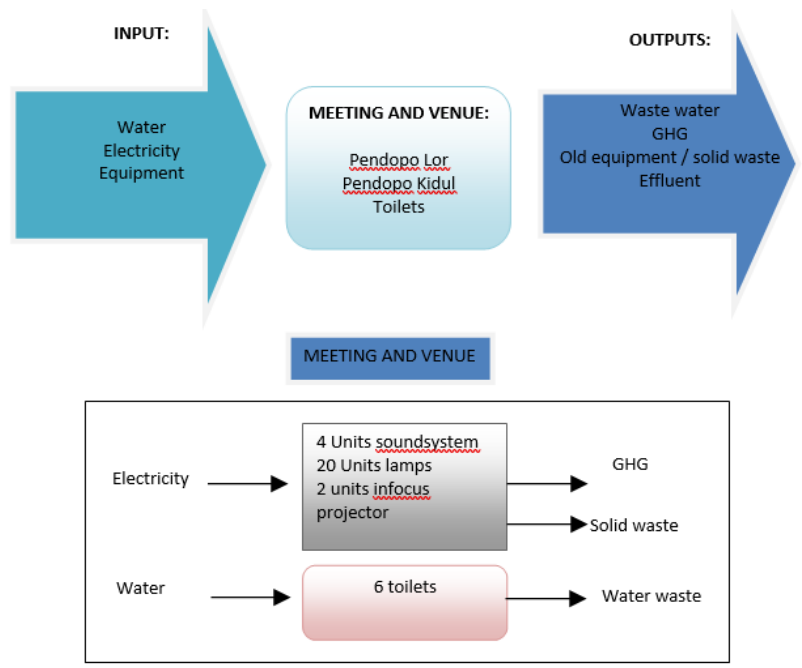

Gambar 3. Alur sumberdaya dan energi di Pendopo

\section{Mengamati Proses Pengoperasian}

Proses pengoperasian diamati untuk melengkapi dan meninjau aktivitas dan alurnya. Mengamati dan menilai pengoperasian, praktik pengerjaan serta prosedur maintenance bertujuan untuk memahami sumber dan penyebab penggunaan sumber daya dan penghasil polusi/limbah.

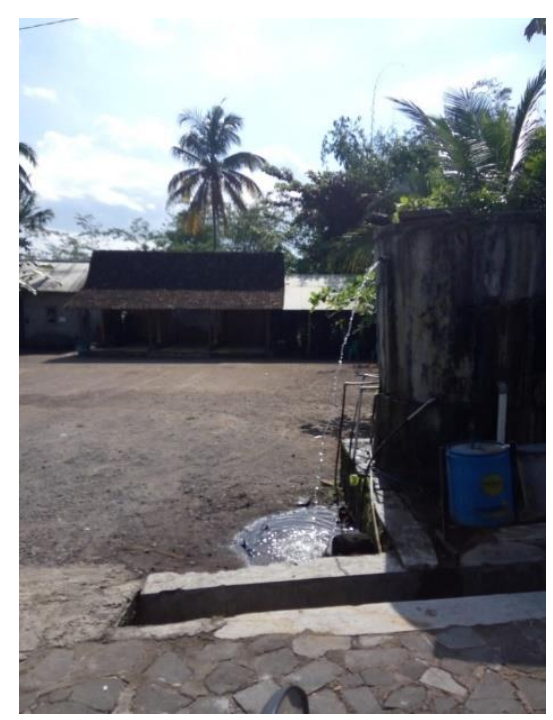

Gambar 4. Salah Satu Dapur Dasa Wisma dan Penampungan Air yang Dibiarkan Meluap 
Tabel 3. Hasil Pengamatan di Lapangan

\begin{tabular}{|c|c|}
\hline $\begin{array}{l}\text { Pengamatan } 1: \\
\text { Penampilan tempat } \\
\text { kerja secara umum, } \\
\text { tata graha dan praktik } \\
\text { operasi standar }\end{array}$ & 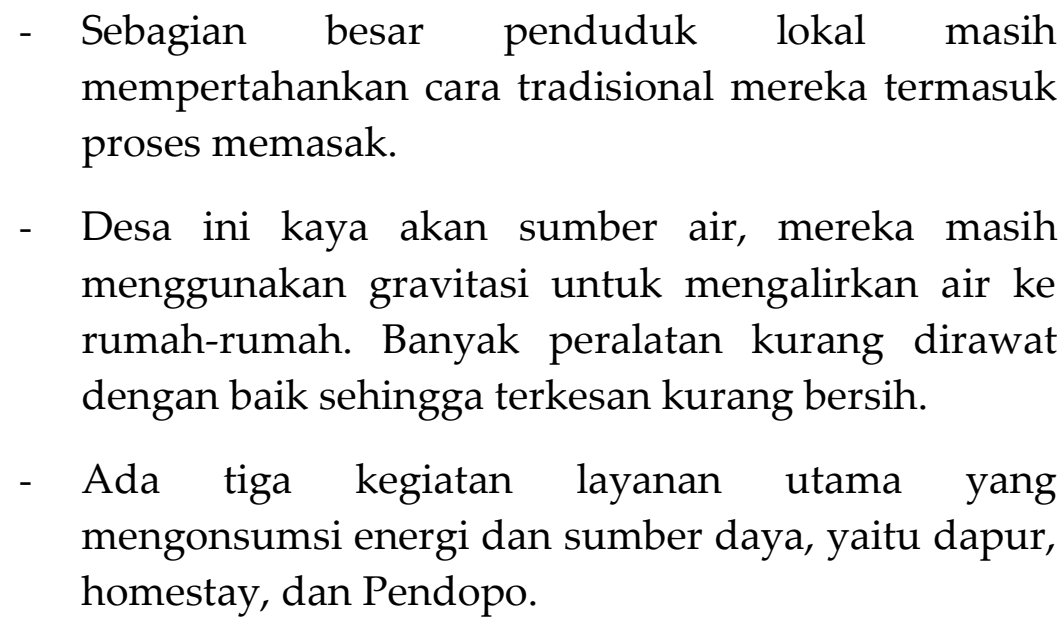 \\
\hline $\begin{array}{l}\text { Pengamatan 2: } \\
\text { Kebocoran, tumpahan } \\
\text { atau kerugian lain } \\
\text { yang diamati }\end{array}$ & $\begin{array}{l}\text { - Terdapat begitu banyak kebocoran di sumber air, } \\
\text { membiarkan air meluap di penampungan. } \\
\text { - Warga selalu membuka keran air mereka sepanjang } \\
\text { hari. } \\
\text { - Menggunakan banyak kayu untuk memasak; } \\
\text { menyebabkan asap dan arang menyebar di dapur, } \\
\text { tidak baik untuk kesehatan dan kebersihan. }\end{array}$ \\
\hline $\begin{array}{l}\text { Pengamatan 3: Tingkat } \\
\text { teknologi, } \\
\text { pemeliharaan } \\
\text { kontrolnya }\end{array}$ & 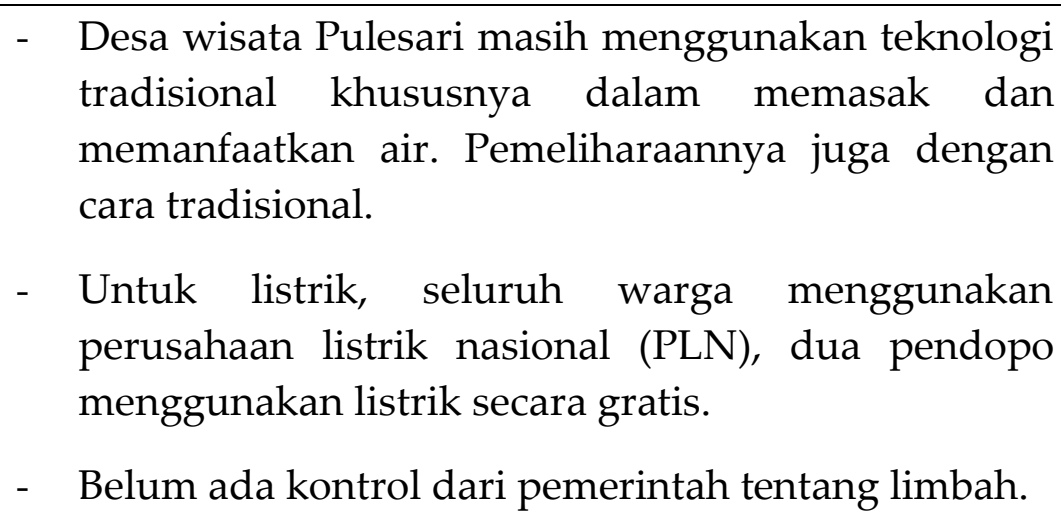 \\
\hline $\begin{array}{l}\text { Pengamatan 4: Bahan } \\
\text { dan limbah } \\
\text { pengguna dan sumber } \\
\text { utama, kontrol saat ini } \\
\text { dan praktik } \\
\text { penanganan } \\
\text { pembuangan }\end{array}$ & $\begin{array}{l}\text { - Dapurnya sangat gelap, penuh asap, abu, dan } \\
\text { dindingnya hitam karena asapnya. Para juru masak } \\
\text { tidak menggunakan sarung tangan dan celemek. } \\
\text { - Mereka mengelola limbah dengan cara yang baik. } \\
\text { Untuk limbah makana diberikan pada ikan, } \\
\text { - Limbah padat dan plastik dipilah dan dikirim ke } \\
\text { bank sampah. }\end{array}$ \\
\hline
\end{tabular}




\begin{tabular}{|c|c|}
\hline $\begin{array}{l}\text { Pengamatan 5: Air dan } \\
\text { limbah cair - pengguna } \\
\text { dan sumber utama, } \\
\text { kontrol saat ini dan } \\
\text { praktik pembuangan }\end{array}$ & $\begin{array}{l}\text { - } \quad \text { Sumber air dari sungai dan sumur. } \\
\text { - } \quad \text { Limbah cair dialirkan ke kebun } \\
\text { - } \quad \text { Limbah kotoran manusia seperti kotoran, air seni, } \\
\text { beberapa penduduk desa mengalirkannya ke septic } \\
\text { tank, beberapa warga membuangnya ke kolam ikan } \\
\text { lele dan mengalir lagi ke kebun dan sungai. }\end{array}$ \\
\hline $\begin{array}{l}\text { Pengamatan 6: Energi - } \\
\text { pengguna utama, } \\
\text { kerugian, } \\
\text { pembuangan energi } \\
\text { limbah }\end{array}$ & $\begin{array}{l}\text { - Pengguna utama sumberdaya dan energi adalah } \\
\text { warga dan wisatawan } \\
\text { - Para tamu merasa mereka bebas untuk } \\
\text { menggunakan dan membuangnya seperti yang } \\
\text { mereka inginkan karena sudah membayar dan } \\
\text { persediaan sumberdaya melimpah }\end{array}$ \\
\hline $\begin{array}{l}\text { Pengamatan 7: Bahan } \\
\text { kimia dan emisi - } \\
\text { pengguna utama, } \\
\text { kerugian, bahaya }\end{array}$ & 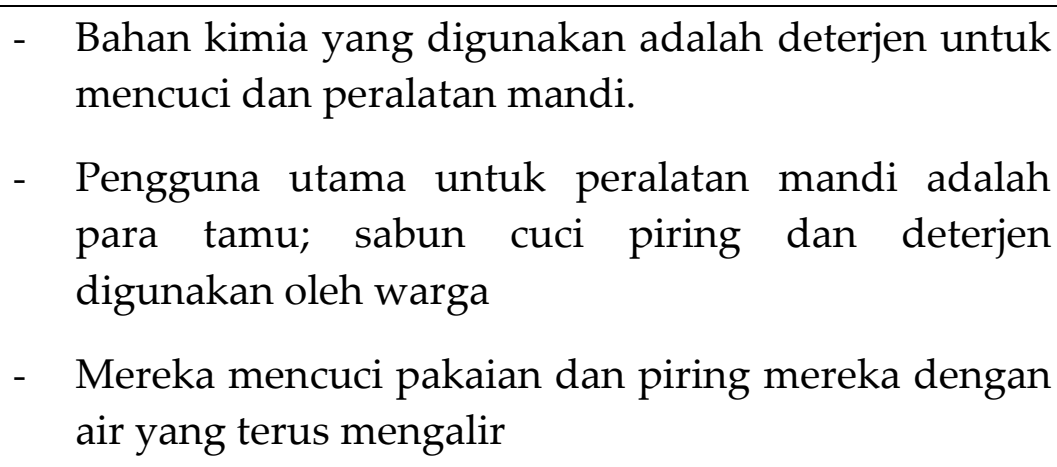 \\
\hline $\begin{array}{l}\text { Pengamatan 8: } \\
\text { Masalah kesehatan } \\
\text { dan keselamatan kerja } \\
\text { diidentifikasi }\end{array}$ & $\begin{array}{l}\text { - } \text { Beberapa toilet dan kamar terlihat bersih } \\
\text { - Masalah kesehatan mungkin terjadi pada ibu-ibu } \\
\text { kelompok dasa wisma karena asap dari tungku } \\
\text { tradisional }\end{array}$ \\
\hline $\begin{array}{l}\text { Pengamatan 9: } \\
\text { Masalah kebersihan } \\
\text { (makanan) } \\
\text { keselamatan } \\
\text { konsumen } \\
\text { diidentifikasi }\end{array}$ & $\begin{array}{l}\text { - Memasak makanan lokal dengan tidak } \\
\text { menggunakan sarung tangan, tanpa celemek. } \\
\text { - } \begin{array}{l}\text { Memasak makanan dengan kayu bakar yang } \\
\text { menghasilkan banyak asap. }\end{array}\end{array}$ \\
\hline
\end{tabular}

\section{Benchmark Kinerja dan Praktik}

Berdasarkan benchmark praktik dan benchmark kinerja, ada beberapa praktik yang dapat diterapkan untuk meningkatkan produktivitas dan meminimalkan 
penggunaan energi, air, dan material di seluruh area aktifitas utama desa wisata. Dari keseluruhan benchmark praktek menunjukkan bahwa ada beberapa praktik yang berpotensi ditingkatkan. Selain itu, benchmark kinerja menunjukkan bahwa konsumsi energi serta limbah yang dihasilkan masih dalam angka ambang batas yang disarankan. Namun demikian, beberapa peningkatan produktivitas potensial dapat dipertimbangkan oleh manajemen Dewi Pule untuk meningkatkan produktifitas dan lebih sadar lingkungan. Daftar benchmark praktek dan kinerja disajikan pada table di bawah ini:

Tabel 4. Benchmark Praktek dan Kinerja

\begin{tabular}{|c|c|c|}
\hline \multicolumn{3}{|l|}{ Aktifitas Utama 1: Dapur } \\
\hline Leading practice (benchmark) & Praktik di Dewi Pule & $\begin{array}{l}\text { Potensi } \\
\text { Perbaikan } \\
\text { (Tinggi, Sedang } \\
\text { atau Rendah) }\end{array}$ \\
\hline $\begin{array}{l}\text { 1.1. Lacak dan pantau limbah, } \\
\text { kurangi limbah dengan jumlah } \\
\text { minimum. }\end{array}$ & $\begin{array}{l}\text { Mengumpulkan limbah } \\
\text { plastik, limbah padat dan } \\
\text { tidak memiliki pengolahan } \\
\text { limbah minyak }\end{array}$ & Tinggi \\
\hline $\begin{array}{l}\text { 1.2. Menggunakan mesin pencuci } \\
\text { piring dan menggunakannya saat } \\
\text { penuh. Sehingga bisa } \\
\text { meminimalkan penggunaan air }\end{array}$ & $\begin{array}{l}\text { Cuci piring manual, air } \\
\text { selalu menyala }\end{array}$ & Tinggi \\
\hline $\begin{array}{l}\text { 1.3. Limbah komunal untuk limbah } \\
\text { air }\end{array}$ & $\begin{array}{l}\text { Tangki septik dan limbah } \\
\text { manual menggunakan } \\
\text { kolam dan lele }\end{array}$ & Tinggi \\
\hline $\begin{array}{l}\text { 1.4. Menggunakan perangkap } \\
\text { minyak untuk minyak, tidak } \\
\text { menuangkan minyak ke drainase, } \\
\text { itu harus ditempatkan dalam } \\
\text { wadah khusus }\end{array}$ & $\begin{array}{l}\text { Buang minyak atau minyak } \\
\text { langsung ke dalam drainase } \\
\text { bersama dengan sisa air } \\
\text { lainnya }\end{array}$ & Tinggi \\
\hline $\begin{array}{l}\text { 1.5. Menggunakan standar } \\
\text { keamanan dan kebersihan di dapur }\end{array}$ & $\begin{array}{llr}\text { Tidak ada } & \text { standar } \\
\text { keamanan } & \text { dan } & \text { kebersihan } \\
\text { di dapur } & & \end{array}$ & Sedang \\
\hline
\end{tabular}




\begin{tabular}{|c|c|c|}
\hline $\begin{array}{l}\text { 1.6. Menggunakan gas dan magic jar } \\
\text { untuk memasak nasi }\end{array}$ & $\begin{array}{l}\text { Menggunakan } \\
\text { kompor/tungku tradisional } \\
\text { dengan kayu bakar dan gas }\end{array}$ & Sedang \\
\hline $\begin{array}{l}\text { 1.7. Menggunakan blower untuk } \\
\text { memaksimalkan api } r \text { dan } \\
\text { meminimalkan abu di kompor }\end{array}$ & $\begin{array}{l}\text { Tidak ada blower, hanya } \\
\text { menggunakan pipa dari } \\
\text { bambu } \\
\text { memaksimalkan api }\end{array}$ & Sedang \\
\hline $\begin{array}{l}\text { 1.8. Menggunakan Light Solar Bottle } \\
\text { untuk meminimalkan lampu di } \\
\text { dapur }\end{array}$ & $\begin{array}{l}\text { Gunakan bola lampu pijar } \\
\text { LED di dapur atau genting } \\
\text { kaca untuk pencahayaan }\end{array}$ & Sedang \\
\hline \multicolumn{3}{|l|}{ Aktifitas utama 2: Homestay } \\
\hline Leading practice (benchmark) & Praktik di Dewi Pule & $\begin{array}{l}\text { Potensi } \\
\text { Perbaikan } \\
\text { (Tinggi, Sedang } \\
\text { atau Rendah) }\end{array}$ \\
\hline 2.1. Menampung Air hujan & $\begin{array}{l}\text { Air hujan dibiarkan } \\
\text { langsung ke tanah }\end{array}$ & Rendah \\
\hline $\begin{array}{l}\text { 2.2. Pemurnian air, memungkinkan } \\
\text { air untuk digunakan kembali }\end{array}$ & $\begin{array}{l}\text { Limbah cair langsung } \\
\text { dibuang ke tanah, kolam }\end{array}$ & Rendah \\
\hline $\begin{array}{l}\text { 2.3. membeli produk dengan desain } \\
\text { kemasan yang dapat digunakan } \\
\text { ulang/didaur ulang }\end{array}$ & $\begin{array}{l}\text { Membeli produk dengan } \\
\text { kemasan plastik (air } \\
\text { mineral, bumbu dapur dll) }\end{array}$ & Rendah \\
\hline $\begin{array}{l}\text { 2.4. Penyimpanan sampah kering } \\
\text { dan basah }\end{array}$ & $\begin{array}{l}\text { Beberapa homestay sudah } \\
\text { ada pemilahan sampah }\end{array}$ & Rendah \\
\hline $\begin{array}{l}\text { 2.5. Mengukur penggunaan listrik, } \\
\text { air, gas, dan material }\end{array}$ & $\begin{array}{lr}\text { Hanya } & \text { mengandalkan } \\
\text { laporan } & \text { tagihan bulanan } \\
\text { dari PLN } & \end{array}$ & Rendah \\
\hline $\begin{array}{l}\text { 2.6. Informasi dan peningkatan } \\
\text { kesadaran di antara karyawan dan } \\
\text { tamu untuk energi }\end{array}$ & $\begin{array}{l}\text { Tidak ada peringatan bagi } \\
\text { tamu untuk menggunakan } \\
\text { sumberdaya dengan bijak } \\
\text { di homestay }\end{array}$ & Rendah \\
\hline
\end{tabular}




\begin{tabular}{|c|c|c|}
\hline \multicolumn{3}{|l|}{ Aktifitas Utama 3: Pendopo } \\
\hline Leading Practice (Benchmark) & Praktik di Dewi Pule & $\begin{array}{l}\text { Potensi } \\
\text { Perbaikan } \\
\text { (Tinggi, Sedang } \\
\text { atau Rendah) }\end{array}$ \\
\hline $\begin{array}{l}\text { 3.1. Mematikan perangkat } \\
\text { elektronik jika tidak digunakan }\end{array}$ & $\begin{array}{l}20 \text { minutes before the } \\
\text { guests (group) come, the } \\
\text { sound system is on. }\end{array}$ & Rendah \\
\hline $\begin{array}{l}\text { 3.2. Peningkatan kesadaran di } \\
\text { antara karyawan dan tamu untuk } \\
\text { energi yang aman }\end{array}$ & $\begin{array}{l}\text { Tidak ada peringatan bagi } \\
\text { wisatawan untuk } \\
\text { menghemat energi }\end{array}$ & Rendah \\
\hline 3.3. Menggunakan lampu LED & $\begin{array}{l}\text { Beberapa homestay sudah } \\
\text { menggunakan LED }\end{array}$ & Sedang \\
\hline
\end{tabular}

5. Menetapkan Prioritas dan Tindakan

Berdasarkan tolok ukur, ada beberapa praktik dan kinerja yang dapat diterapkan di desa wisata Pulesari, dalam rangka penghematan biaya dan produksi yang lebih bersih. Beberapa praktik terbaik adalah menampung hujan, membangun dapur umum dan limbah. Pada area dapur, para juru masak dapat mulai menggunakan sarung tangan dan celemek untuk membuat produksi yang lebih bersih. Kompor atau tungku sehat hemat energi (TSHE) yang efisien dapat meminimalkan abu dan asap. Blower juga dapat membantu memaksimalkan api. Prioritas dan tindakan ditampilkan dalam sistem tabel berwana traffic light agar mudah menentukan mana yang lebih diprioritaskan. 
Tabel 5. Hasil Keseluruhan Temuan Tim RECP dengan Sistem Tabel Traffic Light

\begin{tabular}{|c|l|l|l|l|}
\hline Aktifitas Utama & $\begin{array}{l}\text { Penggunaan } \\
\text { Sumberdaya }\end{array}$ & Beban Lingkungan & Biaya & $\begin{array}{l}\text { Bahaya } \\
\text { (termasuk } \\
\text { kesehatan \& } \\
\text { keselamatan } \\
\text { kerja) }\end{array}$ \\
\hline Dapur & & & \\
\hline$\bullet$ Activity 1: & & & \\
\hline Homestay & & & \\
\hline Pendivity 2: & & & \\
\hline
\end{tabular}

6. Mengembangkan Opsi-opsi RECP

Pada bagian ini, opsi-opsi untuk implementasi dengan kategorisasi atau estimasi seperti biaya rendah atau tanpa biaya lebih didahulukan. Berdasarkan penilaian baseline, maka dapat ditentukan hanya terdapat dua area yang akan dijadikan perhatian, yaitu dapur dan homestay. 
Tabel 6. Opsi RECP untuk Dapur

\begin{tabular}{|c|c|c|}
\hline \multicolumn{2}{|c|}{$\begin{array}{l}\text { Kategori Penyebab } \\
\text { Asal }\end{array}$} & Opsi-opsi \\
\hline \multicolumn{2}{|c|}{ Input Proses } & $\begin{array}{l}\text { Proses memasak harus dilakukan dalam praktik yang lebih } \\
\text { baik dan bersih seperti mengenakan celemek dan sarung } \\
\text { tangan. } \\
\text { Bersihkan peralatan secara langsung setelah selesai } \\
\text { digunakan. } \\
\text { Melapisi tanah dapur dengan keramik. }\end{array}$ \\
\hline \multicolumn{2}{|l|}{ SDM } & $\begin{array}{l}\text { Meningkatkan kesadaran akan sanitasi dan kebersihan } \\
\text { untuk semua staf dan masyarakat setempat. }\end{array}$ \\
\hline \multirow[t]{3}{*}{ Fasilitas } & $\begin{array}{l}\text { Pengawasan } \\
\text { Proses }\end{array}$ & $\begin{array}{l}\text { Mencatat penggunaan bahan, listrik dan peralatan serta } \\
\text { total tamu yang makan siang/malam di desa wisata. } \\
\text { Minimalkan penggunaan plastik untuk makanan }\end{array}$ \\
\hline & Peralatan & $\begin{array}{l}\text { Ganti tungku tradisional dengan tungku sehat hemat energi } \\
\text { (TSHE) yang lebih efisien. } \\
\text { Pasang blower asap agar asapnya tidak tertinggal di dapur. } \\
\text { Tambahkan magnet ke pipa LPG untuk penggunaan LPG } \\
\text { yang lebih efisien. } \\
\text { Menggunakan blower untuk kompor/tungku demi } \\
\text { memaksimalkan api dan meminimalkan asap dan abu }\end{array}$ \\
\hline & Teknologi & Gunakan penanak nasi elektrik (magic jar). \\
\hline \multicolumn{2}{|l|}{ Produk } & $\begin{array}{l}\text { Menggunakan desain kompor TSHE yang lebih efisien dan } \\
\text { tidak menghasilkan banyak asap. } \\
\text { Dapur yang bersih dan cukup cahaya dapat menghasilkan } \\
\text { produk yang baik. } \\
\text { Desain kemasan yang lebih kreatif diperlukan untuk } \\
\text { menarik wisatawan }\end{array}$ \\
\hline \multirow[t]{2}{*}{ Limbah } & $\begin{array}{l}\text { Nilai } \\
\text { internal }\end{array}$ & Tidak ada \\
\hline & $\begin{array}{l}\text { Nilai } \\
\text { Eksternal }\end{array}$ & Tidak ada \\
\hline
\end{tabular}


Tabel 7. Opsi RECP untuk Homestay

\begin{tabular}{|c|c|c|}
\hline \multicolumn{2}{|c|}{$\begin{array}{l}\text { Kategori Penyebab } \\
\text { Asal }\end{array}$} & Opsi-opsi \\
\hline \multicolumn{2}{|c|}{ Input Proses } & $\begin{array}{l}\text { Mencatat secara individu/manual penggunaan listrik, air, } \\
\text { gas, bahan makanan dan total tamu yang tinggal di } \\
\text { homestay }\end{array}$ \\
\hline \multicolumn{2}{|l|}{ SDM } & $\begin{array}{l}\text { Ganti seprei tempat tidur saat tamu baru datang. } \\
\text { Memberikan informasi pada wisatawan untuk menghemat } \\
\text { energi dan sumber daya. }\end{array}$ \\
\hline \multirow[t]{3}{*}{ Fasilitas } & $\begin{array}{l}\text { Pengawasan } \\
\text { Proses }\end{array}$ & Mengalirkan air limbah ke kolam ikan atau kebun \\
\hline & Peralatan & Gunakan lampu LED agar lebih efisien \\
\hline & Teknologi & Tidak ada \\
\hline \multicolumn{2}{|l|}{ Produk } & $\begin{array}{l}\text { Bersihkan ruangan sebelum tamu datang, } \\
\text { Cat dinding kamar dengan warna putih }\end{array}$ \\
\hline \multirow[t]{2}{*}{ Limbah } & $\begin{array}{l}\text { Nilai } \\
\text { Internal }\end{array}$ & $\begin{array}{l}\text { Pisahkan limbah rumah tangga, setidaknya dua tempat } \\
\text { sampah. }\end{array}$ \\
\hline & $\begin{array}{l}\text { Nilai } \\
\text { External }\end{array}$ & Tidak ada \\
\hline
\end{tabular}

7. Mengevaluasi Kelayakan

Bagian ini menjelaskan opsi rekomendasi dengan perkiraan biaya investasi dan penghematan. Bagian ini juga menjelaskan manfaat lingkungan dari rekomendasi RECP yang diberikan di desa wisata Pulesari. Terdapat tiga opsi RECP yang dapat dipertimbangkan oleh pihak manajemen Dewi Pule untuk dapat diterapkan yaitu penggunaan tungku sehat hemat energi (TSHE), mengganti semua lampu pijar dengan lampu LED dan penggunaan magnet pada selang gas. Opsi tersebut dipilih karena mudah didapatkan bahan-bahannya, mudah pemasangan dan penggunaannya serta biaya yang dikeluarkan dapat dijangkau. 
a. Menggunakan kompor tungku sehat hemat energi (TSHE) model Keren.

Keuntungan dari kompor model Keren ini dapat menghemat 26,8\% penggunaan kayu bakar disbanding dengan kompor tradisional yang ada di Pulesari. Kompor TSHE hanya membutuhkan sedikit pasokan kayu bakar, karena lubang kompornya tidak terlalu besar tetapi dapat memaksimalkan api dan panas serta meminimalkan asap dan residu abu/arang selama proses memasak¹.

Table 7. Potensi Penghematan Energi pada TSHE

\begin{tabular}{|l|l|l|l|}
\hline Deskripsi & Unit & Kondisi Sekarang & $\begin{array}{l}\text { Setelah } \\
\text { Implementasi } \\
\mathbf{( 2 6 . 8 \% )}\end{array}$ \\
\hline TSHE & & Old stove & Installed \\
\hline Kayu bakar per hari & $\mathrm{Kg}$ & 40.9 & 10.96 \\
\hline Emisi per hari & $\mathrm{Kg} \mathrm{CO}$ eq & 158 & 42.34 \\
\hline Harga kayu bakar & $\mathrm{Rp}$ & $14,934,571$ & $4,002,465$ \\
\hline per tahun & & & $10,931.75$ \\
\hline Potensi penghematan kayu bakar per tahun (kg/tahun) & $42,215.9$ \\
\hline Pengurangan Emisi (kg/tahun) & $10,932,106$ \\
\hline Penghematan Biaya (Rp/tahun) & & \\
\hline
\end{tabular}

\footnotetext{
${ }^{1}$ http://tungkuindonesia.org/id/page/87/Daftar-Tungku-yang-Lulus-Uji.html
} 
Tabel 8. Estimasi Investasi untuk Kompor TSHE

\begin{tabular}{|l|l|l|l|}
\hline Komponen Biaya & Jumlah & Harga per unit (Rp) & $\begin{array}{l}\text { Total } \\
\text { (IDR) }\end{array}$ \\
\hline TSHE & 6 Diaya \\
\hline Total estimasi biaya investasi 24 TSHE & 145,000 & $3,480,000$ \\
\hline Net Present Value (Rp/tahun) & $3,480,000$ \\
\hline Jangka Waktu Pengembalian (tahun) & 7.452 .106 \\
\hline
\end{tabular}

\section{b. Penggunaan Lampu LED}

Diharapkan penggunaan lampu LED dapat menghemat lebih banyak energi dan biaya. Lampu LED juga ramah lingkungan karena watt nya yang kecil. Lampu biasa dengan tenaga 15 watt dapat diganti dengan lampu LED bertenaga 5 watt. Lampu LED diharapkan dapat digunakan minimal di 40 homestay pada tahap awal, di setiap homestay setidaknya ada 5 hingga 10 lampu LED sebagai model terutama lampu yang memiliki watt tinggi. Satu lampu LED dengan merk tertentu dapat bertahan hingga 1 tahun. 
Tabel 9. Potensi Penghematan Lampu LED

\begin{tabular}{|l|l|l|l|}
\hline Deskripsi & Unit & $\begin{array}{l}\text { Kondisi } \\
\text { Sekarang }\end{array}$ & Paran \\
\hline Penggantian lampu & & Incandescent & LED \\
\hline Konsumsi Tenaga & & $15 \mathrm{~W}$ & 5 Watt \\
\hline Jumlah Lampu & Watt & 15 & 5 \\
\hline Lama beroperasi /tahun (@14 jamhari) & jam & 5110 & 560 \\
\hline KOnsumsi Energi/tahun & unit & 560 & 5110 \\
\hline Menghasilkan Emisi (CO 2$) /$ tahun & kg & 30166 & 14308 \\
\hline Biaya Energi/tahun @(Rp 1.500/kWh) & IDR & 64386000 & 21462000 \\
\hline Potensi Penghematan Energi kWh /tahun & 42924 & 28616 \\
\hline Pengurangan Emisi (CO 2$)$ kg/tahun & & & 10055 \\
\hline
\end{tabular}


Table 10. Estimasi Biaya Investasi untuk Lampu LED

\begin{tabular}{|l|l|l|l|}
\hline Komponen Biaya & $\begin{array}{l}\text { Jumlah } \\
(\text { unit })\end{array}$ & $\begin{array}{l}\text { Harga per Unit } \\
(\mathrm{Rp})\end{array}$ & Total Biaya (Rp) \\
\hline $\begin{array}{l}\text { Pembelian Lampu Phillips } \\
\text { LED 5 Watt }\end{array}$ & 40.000 & 22.400 .000 \\
\hline Total Estimasi Biaya Investasi & 22.400 .000 \\
\hline Net Present Value & 20.524 .000 \\
\hline Jangka Waktu Uang Kembali (year) & 1,091 \\
\hline
\end{tabular}

c. Penggunaan Magnet Pada Selang Gas LPG

Dengan menempelkan magnet pada selang LPG maka dapat menghemat penggunaan gas sebanyak 20\% hingga 50\%. Dalam kasus Dewi Pule, diasumsikan menghemat $30 \%$ gas. Teknik ini telah terbukti dengan membandingkan dua kompor gas dalam air mendidih, satu kompor menggunakan magnet dan kompor lainnya tanpa magnet. Kompor yang menggunakan magnet direbus lebih cepat daripada yang tidak menggunakan magnet. Pembakaran menjadi lebih baik karena peningkatan struktur ion yang disebabkan oleh magnet. Kemudian, panas juga berada pada performa maksimal karena ion yang ditingkatkan. Diperlu dua pasangan magnet untuk setiap gas dengan kekuatan tertentu (lihat Harianto \& Santoso, 2016) 
Table 11. Potensi Penghematan Energi pada Gas Menggunakan Magnet

\begin{tabular}{|l|l|l|l|}
\hline Deskripsi & Unit & $\begin{array}{l}\text { Kondisi } \\
\text { Sekarang }\end{array}$ & $\begin{array}{l}\text { Saran Penerapan } \\
(30 \%)\end{array}$ \\
\hline $\begin{array}{l}\text { Magnet untuk Kompor Gas Dasa } \\
\text { Wisma }\end{array}$ & - & $\begin{array}{l}\text { Dua Pasang } \\
\text { Magnet }\end{array}$ \\
\hline Gas LPG per tahun (6 Dasa Wisma) & $\mathrm{kg}$ & 432 & 129,6 \\
\hline Konsumsi Energi /tahun & $\mathrm{kWh}$ & 5875,2 & 1762,56 \\
\hline Menghasilkan Emisi (CO 2$) /$ tahun & $\mathrm{kg}$ & 4192 & 1239 \\
\hline Biaya Energi /tahun & $\mathrm{Rp}$ & 2.880 .000 & 864.000 \\
\hline Potensi Penghematan Energi kWh/tahun & 29112,64 \\
\hline Pengurangan Emisi (CO 2 ) kg/tahun & & 2.016 .000 \\
\hline Penghematan Biaya Energi Rp/tahun & & \\
\hline
\end{tabular}

Table 12. Estimasi Biaya Investasi Magnet

\begin{tabular}{|l|l|l|l|}
\hline Komponen Biaya & $\begin{array}{l}\text { Jumlah } \\
\text { (pasang) }\end{array}$ & $\begin{array}{l}\text { Harga per pasang } \\
\text { (IDR) }\end{array}$ & Total Biaya (Rp) \\
\hline Oval Magnet & 12 & 5.000 & 60.000 \\
\hline Total Estimasi Investasi Biaya & 60.000 \\
\hline Net Present Value & 0,03 \\
\hline Payback Period & \\
\hline
\end{tabular}




\section{Pembahasan}

Berdasarkan hasil analisis yang dilakukan, beberapa opsi dapat diterapkan agar menunjang produktifitas para pengelola dan staf baik pemandu, pemilik homestay maupun ibu-ibu PKK yang bergerak dalam bidang kuliner di dasa wisma. Namun demikian, secara umum apabila skala kunjungan wisatawan semakin bertambah maka semakin banyak pula pelayanan yang diberikan dan semakin banyak pula limbah yang dihasilkan.

Secara keseluruhan, sebenarnya Desa Wisata Pulesari dapat berhemat lebih banyak energi yang tentunya akan menghemat pengeluaran juga. Dari keseluruhan penghematan energi baik dari penggunaan TSHE, Lampu LED dan penggunaan magnet, desa wisata Pulesari dapat mengurangi karbon sebanyak 65279,9 CO2eq $\mathrm{kg} /$ tahun. Sedangkan dari segi penghematan ekonomi, dari total tiga opsi yang diiberikan hanya dengan berinvestasi sebesar Rp. 25.940.000, Dewi Pule dapat menghemat total Rp. 33.412.106,- /tahun. 
Tabel 13. Kesimpulan Semua Opsi yang Diberikan

\begin{tabular}{|c|c|c|c|c|c|c|}
\hline \multirow{2}{*}{$\begin{array}{l}\text { Deskripsi } \\
\text { Opsi }\end{array}$} & \multicolumn{4}{|l|}{ Ekonomi } & \multicolumn{2}{|l|}{ Lingkungan } \\
\hline & $\begin{array}{l}\text { Investasi } \\
(\mathrm{Rp})\end{array}$ & $\begin{array}{l}\text { Pendapatan } \\
\text { (Rp/tahun) }\end{array}$ & $\begin{array}{l}\text { Pay } \\
\text { back } \\
\text { (tahun) }\end{array}$ & NPV & $\begin{array}{l}\text { Konservasi } \\
\text { Sumberdaya } \\
\text { (kg/tahun) }\end{array}$ & $\begin{array}{l}\text { Pengurangan } \\
\text { Emisi } \\
\text { (CO2 eq } \\
\text { kg/tahun) }\end{array}$ \\
\hline $\begin{array}{l}\text { Kompor } \\
\text { TSHE }\end{array}$ & 3.480 .000 & 10.932 .106 & 0,46 & 7.452 .106 & 10931,75 & 42215,9 \\
\hline $\begin{array}{l}\text { lampu } \\
\text { LED }\end{array}$ & 22.400 .000 & 20.524 .000 & 1,091 & 20.524 .000 & 28616 & 20111 \\
\hline Magnet & 60.000 & 1.956 .000 & 0,03 & 1.416 .000 & 4112,64 & 2953 \\
\hline Total & 25.940 .000 & 33.412 .106 & 3,071 & 29.392.106 & 43660,39 & 65279.9 \\
\hline
\end{tabular}

Jika melihat penggunaan sumberdaya yang digunakan warga, kayu bakar untuk kebutuhan sehari-hari biasanya diambil dari ranting pohon yang sudah tua, atau menebang pohon yang layak tebang. Hampir semua warga Pulesari memiliki gudang penyimpanan kayu bakar di rumah masing-masing. Mereka terpaksa membeli kayu bakar apabila terdapat rombongan yang menginap dalam jumlah besar. Walaupun mayoritas sumberdaya kayu bakar mereka dapatkan tanpa biaya banyak, tim ahli juga harus menghitungkan dan mempertimbangkan banyak aspek selain aspek ekonomi.

Masalah higienitas kemudian muncul dikalangan penduduk karena menggunakan kayu bakar untuk memasak yang cenderung mengeluarkan banyak asap dan sisa residu dari kayu bakar yang dalam jangka panjang dapat merusak kesehatan dan makanan yang disajikan juga dapat mengandung racun amoniak 
karena asap. Disamping itu dinding atap dan tembok menghitam serta peralatan yang cepat rusak karena terkena asap.

Selanjutnya, mengenai sampah rumah tangga di desa wisata Pulesari hampir semuanya zero waste, plastik masuk bank sampah, sisa makanan diberikan pada ikan atau dijadikan pupuk. Sisa air mandi dan cuci kembali ke lahan kebun salak, diserap tanah dan mengalir ke sungai. Di beberapa rumah sudah teradpat program pemilahan sampah rumah tangga dengan membaginya menjadi dua bagian. Sampah bekas makanan dan sampah yang dapat dikirim ke bank sampah Dewi Pule.

\section{Simpulan dan Saran}

Berdasarkan hasil temuan, terdapat ketidakefisienan penggunaan sumberdaya dan energi di dapur dan homestay. Penggunaan energi di homestay dapat dihemat dengan cara mengganti lampu biasa dengan lampu LED. Efisiensi di dapur dapat dilakukan dengan menggunakan magnet pada selang gas dan menggunakan kompor tungku sehat hemat energi (TSHE). Dari hasil rekomendasi tersebut, Dewi Pule berpotensi mengurangi karbon sebanyak 65.279,9 CO2eq kg/tahun dan dari segi ekonomi Dewi Pule berpotensi menghemat total Rp. 33.412.106 /tahun.

Program ESPB yang dimiliki oleh UNIDO dapat menggambarkan siklus penggunaan sumberdaya dan energi dari proses awal hingga akhir berupa limbah padat, cair dan emisi gas, ketidakefisienan penggunaan sumberdaya dan energi dapat dipetakan dan ditemukan secara terperinci. Meskipun demikian, penilaian ESPB di desa wisata memerlukan penyesuaian pada indikator-indikator yang dinilai. Hal ini dikarenakan karakter penggunaan sumberdaya dan energi di desa wisata sangat berbeda dengan industri yang menerapkan metode ESPB dari UNIDO. Berbeda dengan industri yang berorientasi pada bisnis dengan manajemen 
pengelolaan yang ketat, penggunaan sumberdaya dan energi di Dewi Pule hanyalah roda kehidupan masyarakat setempat dalam menjalankan kesehariannya.

Proses penilaian ESPB di desa wisata menjadi tantangan tersendiri Data dasar konsumsi sumberdaya dan energi di desa wisata merupakan kunci awal pemetaan ESPB, akan tetapi sumberdaya berupa air dan bahan bakar kayu yang melimpah di Dewi Pule tidak terukur dengan baik sehingga ketidakefisienan yang ditemukan bukan menjadi perhatian bagi pihak pengelola. Kajian mengenai ESPB di Desa Wisata Pulesari ini lebih mengarah kepada produksi bersih mengingat beberapa sumberdaya di Pulesari didapatkan dengan cuma-cuma.

Studi lebih lanjut perlu dilakukan untuk melihat keberhasilan rekomendasi program ESPB yang telah dilaksanakan. Perlu adanya pengukuran manfaat yang diterima oleh masyarakat dari sisi ekonomi dan dampak langsung terhadap sumberdaya alam dan energi yang dikonsumsi dalam pengelolaan desa wisata Pulesari.

\section{Ucapan Terima Kasih}

Penulis mengucapkan terima kasih banyak kepada Tuhan yang Maha Kuasa, kedua orang tua penulis, para national expert team dan Project Manager UNIDO di Sleman dan Magelang atas kerjasamanya selama pekerjaan. Dinas Pariwisata Sleman yang selalu memberikan dukungannya, Prof. Dr. M. Baiquni, M.A. yang juga selalu memberikan nasihat serta bimbingannya kepada penulis, teman-teman di organisasi Sustainbale Tourism Organization for Regional Management (STORM) dan semua teman-teman Kajian Pariwisata UGM. 


\section{Daftar Pustaka}

Agyeiwaah, E. (2019). Exploring the relevance of sustainability to micro tourism and hospitality accommodation enterprises (MTHAEs): Evidence from home-stay owners. Journal of Cleaner Production, 226, 159-171. https://doi.org/10.1016/j.jclepro.2019.04.089

Ahmad, F., Draz, M. U., Su, L., Ozturk, I., \& Rauf, A. (2018). Tourism and environmental pollution: Evidence from the One Belt One Road provinces of Western China. Sustainability (Switzerland), 10(10), 1-22. https://doi.org/10.3390/su10103520

Berkel, R. Van. (2014). Cleaner Production Opportunities for Small to Medium Sized Enterprises Cleaner Production Opportunities for Small to Medium Sized Enterprises, (June).

Damanik, J. 2013. Pariwisata Indonesia; Antara Peluang dan Tantangan. Pustaka Pelajar. Yogyakarta.

Dewi, M. H. U., Fandeli, C., \& Baiquni, M. (2013). Tabanan , Bali. Kawistara, 3(2), 117226. https://doi.org/https://doi.org/10.22146/kawistara.3976

Harianto, A., \& Santoso, H. (2016). Pengaruh Medan Magnet Dengan Jarak, 17(2), 137-146.

Hens, L., Block, C., Cabello-Eras, J. J., Sagastume-Gutierez, A., Garcia-Lorenzo, D., Chamorro, C., ... Vandecasteele, C. (2018). On the evolution of "Cleaner Production" as a concept and a practice. Journal of Cleaner Production, 172, 33233333. https://doi.org/10.1016/j.jclepro.2017.11.082

Krisnani, H., \& Darwis, R. S. (2010). 53 pengembangan desa wisata melalui konsep community based tourism, 341-346.

Priasukmana, S., \& Mulyadin, R. M. (2001). Pembangunan desa wisata : Pelaksanaan undang-undang otonomi daerah. Info Sosial Ekonomi , 2(1), 37-44.

Sunlu, U. (2003). Environmental impacts of tourism Local resources and global trades: Environments and agriculture in the Mediterranean region Bari: CIHEAM Options Méditerranéennes: Série A ENVIRONMENTAL IMPACTS OF TOURISM. Séminaires Méditerranéens, 57, 263-270. Retrieved from http://om.ciheam.org/article.php?IDPDF=4001977http://www.ciheam.org/\%5C nhttp://om.ciheam.org/

Syafi, M., \& Suwandono, D. (2015). Tourism Village Planning Concept Approach Community Based Tourism (Case Study Bedono Village, Sayung, Demak), 11(2), 51-60. https://doi.org/10.14710/RUANG.1.4.51-60 
UNIDO, \& UNEP. (2015). National Cleaner Production Centres 20 years of achievement.

Zakaria, F., \& Suprihardjo, D. (2014). Konsep Pengembangan Kawasan Desa Wisata di Desa Bandungan Kecamatan Pakong Kabupaten Pamekasan. Jurnal Teknik ITS, 3(2). https://doi.org/10.12962/j23373539.v3i2.7292

\section{Profil Penulis}

Muhammad Dzulkifli, S.Pd., M.Sc. adalah Dosen Jurusan Bahasa, Komunikasi dan Pariwisata di Politeknik Negeri Jember. Menyelesaikan studi Masternya dalam bidang Kajian Pariwisata Universitas Gadjah Mada pada tahun 2017. Sebelum menjadi dosen Ia aktif sebagai fasilitator program Pariwisata Berkelanjutan Kemeterian Pariwisata di Kabupaten Sleman dan Tenaga Ahli UNIDO 2017-2019 dalam program RECP di Sleman serta menjadi tenaga ahli dalam beberapa kegiatan rencana induk pembangunan kepariwisataan daerah (RIPPARDA) di berbagai daerah di Indonesia. Ketua Sustainable Tourism Organization for Regional Management (STORM) di Yogyakarta yang programnya memberikan pendampingan bagi Desa Wisata di DIY. Minat risetnya adalah mengenai Pariwisata Berkelanjutan, Desa Wisata, Community Development dan Education for Sustainable Development.

Jussac Maulana Masjhoer, S.Kel., M.Sc.adalah seorang dosen di Sekolah Tinggi Pariwisata Ambarrukmo Yogyakarta. Menyelesaikan Studi S2 Magister Pengelolaan Lingkungan Universitas Gadjah Mada pada tahun 2012. Saat ini tengah melanjutkan pendidikan Doktoral Ilmu Lingkungan di Universitas Diponegoro Semarang. Minat riset berhubungan dengan pengelolaan lingkungan di kawasan pesisir dan pulaupulau kecil dan wisata bahari serta pariwsata berkelanjutan. Jussac juga sebagai salah satu tenaga ahli UNIDO 2017-2019 di Sleman dan beberapa kali dipercaya DInas Pariwisata Sleman sebagai tenaga ahli dalam Kajian Penerapan pariwisata Berkelanjutan di Kabupaten Sleman. 